\title{
A BOA-FÉ OBJETIVA COMO LIMITE PARA A ATUAÇÃO DOS ADMINISTRADORES
}

\section{A GOOD FAITH AS STRICT LIMIT FOR PERFORMANCE MANAGEMENT}

\section{Resumo}

Este estudo objetiva traçar uma breve análise a respeito da atuação dos administradores das companhias com ações no Mercado de Capitais, à luz da aplicação da boa-fé objetiva como limite ao papel que estes atores desempenham no desenvolvimento e crescimento das empresas que gerenciam. Os conflitos decorrentes da separação entre a propriedade e o controle das empresas e a consequente crise da legitimação das condutas e decisões tomadas pelos executivos figuram como o foco da razão das regras de governança corporativa e, consequentemente, são a base argumentativa das ideias apresentadas neste trabalho.

Palavras-chave: Governança Corporativa - Boa-fé - Mercado de Capitais Administradores.

\begin{abstract}
This study aims to draw a brief analysis about the actions of the directors of companies with shares in the Stock Market, in light of the application of objective good faith as the limit to the role that those actors play in the development and growth of the companies they manage. The conflicts resulting from the separation of ownership and control of companies and the consequent crisis of legitimization of the actions and decisions taken by the executive figure as the focus of the existence of corporate governance rules, and as a logical and legal result, are the argumentative basis of the ideas presented on this paper.
\end{abstract}

Keywords: Corporate Governance - Good faith - Stock Market - Directors. 


\section{INTRODUÇÃO}

O presente trabalho traça pontuais considerações a respeito da governança corporativa, seu conceito e perspectiva histórica, bem como objetivos e implicações, sob um enfoque jurídico atrelado a reflexões sobre o papel da boa-fé objetiva na limitação da conduta dos executivos das companhias e finaliza com breves apontamentos acerca do panorama do mercado de capitais brasileiro.

O objetivo central é estabelecer limites para a atuação dos administradores das companhias tendo por diretriz os preceitos da aplicação da boa-fé objetiva. Os argumentos fundamentais que se prestam a sustentar a obrigação dos administradores de agirem de acordo com a boa-fé objetiva são a correspondência entre os deveres decorrentes deste instituto jurídico e os consagrados princípios que estão na base das regras de governança corporativa e a natureza contratual de que se reveste a relação dos executivos com os acionistas.

Para tanto, analisar-se-á como se deu historicamente o surgimento da governança corporativa e quais questões estão no centro desta discussão. Serão brevemente abordados os conflitos de interesse que podem surgir no interior da companhia e que influenciam diretamente no modelo de governança a ser implantado na empresa, mantendo estreita relação com o padrão de propriedade acionária do país.

Posteriormente, uma análise, voltada para o âmbito jurídico, dos princípios básicos de governança corporativa seguida pela estruturação da boa-fé objetiva como diretriz para as condutas dos administradores como agentes fiduciários e representantes dos interesses diretos dos sócios, bem como uma comparação com as tendências da Suprema Corte de Delaware neste sentido.

E, finalmente, apontamentos a respeito das características do mercado de capitais brasileiro e suas iniciativas de autorregulação para a adoção, por parte das empresas listadas em bolsa, das práticas de governança corporativa como forma de desenvolvimento das técnicas de proteção aos investidores e consequente dispersão do controle da propriedade.

\section{GOVERNANÇA CORPORATIVA: CONTORNOS GERAIS}


"O século XIX foi a era dos empreendedores, do lançamento das bases de formação do novo mundo corporativo. $O$ século XX foi a era do gerenciamento, do surgimento de uma nova classe - a direção executiva dos grandes conglomerados. $O$ século XXI será a era da governança corporativa, da definição da forma pela qual a estratégia será definida e o poder será exercido em todas as corporações do mundo." Rolf Carlsson

Estabelecer o conceito de governança corporativa é tarefa que requer considerável número de páginas, tendo em vista que o tema pode ser tratado sob diferentes perspectivas, segundo o campo de análise esteja inserido na área econômica, da administração, jurídica, entre outras.

Abordando uma visão geral, governança corporativa consiste no agrupamento de regras, técnicas e mecanismos que estruturam o sistema pelo qual uma companhia deve ser dirigida, considerando o controle da atuação de seus agentes bem como o direcionamento dos distintos interesses derivados das relações organizacionais, na busca de decisões que visem o melhor desenvolvimento para a empresa. ${ }^{1}$

O surgimento deste tema como matéria de alta relevância para as companhias tem início nas décadas de 1980 e 1990, mas as bases teóricas que sustentam tal discussão já haviam sido elaboradas por Adolf A. Berle e Gardner C. Means, em 1932, na obra The modern corporarion and private property, que tratou da separação entre a propriedade e o controle identificando a mudança no comando das companhias com a introdução da figura dos gestores. $^{2}$

De fato, a governança corporativa lida com os conflitos de interesses decorrentes das relações entre os investidores de capitais e os administradores da empresa, na medida em que estas duas figuras não mais se confundem em uma única pessoa. São os chamados conflitos de agência, cuja regulação é necessária à boa organização da companhia e, consequentemente, ao bom desempenho desta diante do mercado. ${ }^{3}$

\footnotetext{
${ }^{1}$ SILVA, Edson Cordeiro da. Governança corporativa nas empresas: guia prático de orientação para acionistas e conselho de administração : novo modelo de gestão para redução do custo de capital e geração de valor ao negócio. São Paulo: Atlas, 2006. p. 2.

${ }^{2}$ Ressalte-se aqui a grandiosa contribuição de J. K. Galbraith na obra The new industrial state, de 1967, ao descrever as novas realidades corporativas: "O poder passou, assim, para um novo fator de produção - a tecnoestrutura das organizações, uma associação de pessoas de diversos conhecimentos técnicos, experiências e talentos. É da eficiência dessa organização que passou a depender o êxito das grandes companhias." ROSSETTI, José Paschoal; ANDRADE, Adriana. Governança corporativa: fundamentos, desenvolvimento e tendências. 5. ed. atual. e ampl. São Paulo: Atlas, 2011. p. 72-80.

${ }^{3}$ LAUTENSCHLEGER JÚNIOR, Nilson. Os desafios propostos pela governança corporativa ao direito empresarial brasileiro: ensaio de uma reflexão crítica e comparada. São Paulo: Malheiros Editores, 2005. p. 44-45.
} 
Historicamente, a evolução do sistema capitalista e a posterior ascensão do capital como fator de produção contribuíram para o surgimento de dois atores distintos no mundo corporativo: o proprietário (principal, investidor, acionista) e o administrador (board of directors, agente, representante), este último incumbido de conferir os melhores retornos, qualitativa e quantitativamente, aos valores empregados pelo primeiro pela fiscalização da diretoria executiva. ${ }^{4}$ No entanto, as divergências que podem surgir das distintas visões que estes personagens carregam suscitam problemas no momento de tomada de decisões pela empresa, situações que devem ser solucionadas através do emprego de adequados padrões de governança corporativa que estabeleçam o limite funcional de cada órgão da companhia.

Em resposta aos escândalos corporativos ocorridos na Inglaterra na década de 1990 (Polly Peck, BCCI, Maxwell), foi editado o Relatório Cadbury (Cadbury Code of Best Practice), cuja repercussão teve impacto internacional no mercado de capitais de diversos países. ${ }^{5}$ Seu conteúdo evidenciava as lacunas do sistema corporativo da época, bem como trazia um modelo elucidativo de práticas consideradas adequadas à consolidação da governança corporativa nas companhias (especialmente inglesas). ${ }^{6}$

A partir deste marco, e em conjunto com a posterior criação dos Princípios OCDE de Governança Corporativa (Principles of Corporate Governance) ${ }^{7}$ em 1999, inúmeros códigos contendo normas estruturais de governança corporativa foram elaborados ao redor do mundo, evidenciando as peculiaridades do mercado financeiro de cada país em suas regulamentações.

\subsection{Conflitos de agência}

\footnotetext{
${ }^{4}$ ROSSETTI, José Paschoal; ANDRADE, Adriana. Obra citada, p. 38.

${ }^{5}$ Estudos apontam The Role and Composition of The Board of Directors of the Large Publicy Owned Corporation como o primeiro código contendo normas de governança corporativa, editado nos Estados Unidos, em 1978, por uma associação de executivos norte-americanos, a Business Roundtable. A melhor doutrina considera o Relatório Cadbury como o marco para a disseminação dos Códigos de Governança Corporativa, não obstante antes de sua elaboração tenham sido editadas normas em outras partes do mundo, como em Hong Kong, 1989. ROSSONI, Luciano; MACHADODA-SILVA, Clóvis L. Institucionalismo Organizacional e Práticas de Governança Corporativa. Revista de Administração Contemporânea, Curitiba, Edição Especial 2010, p. 173-198.

${ }^{6}$ LAUTENSCHLEGER JÚNIOR, Nilson. Os desafios propostos pela governança corporativa ao direito empresarial brasileiro: ensaio de uma reflexão crítica e comparada. São Paulo: Malheiros Editores, 2005. p. 35.

${ }^{7}$ Conferir versão atualizada em 2004, disponível em: 〈http://www.oecd.org>.
} 
O foco da governança corporativa está, indubitavelmente, nos problemas decorrentes da relação entre executivos e acionistas, situação propiciada pelo divórcio entre a propriedade e o controle da companhia. Alexandre Di Miceli da Silveira aponta, no entanto, uma característica intrínseca à natureza humana como a verdadeira razão do problema corporativo: a busca pela maximização pessoal. Ainda que tal constatação se mostre adequada ao desenvolvimento econômico e à dinâmica de mercado, explica o autor que

\begin{abstract}
a busca pela maximização da utilidade pessoal pode levar um indivíduo a tomar decisões prejudiciais a terceiros, principalmente a investidores que confiaram a essa pessoa poder para tomada de decisões em seu interesse. Tem-se então um problema de "governo" ou de direcionamento em tais organizações. ${ }^{8}$
\end{abstract}

Este problema de governo, porém, possui distintas características quando analisada a estrutura da propriedade predominante no mercado de capitais de determinado país. Por exemplo, países pertencentes ao sistema do Direito Romano Germânico, do qual se pode tomar como ilustração a Alemanha e o Brasil, em geral, possuem uma alta concentração acionária, em virtude do menor grau de desenvolvimento de seu mercado de capitais, se comparados com países do modelo anglo-saxão, como Estados Unidos e Inglaterra, cuja dispersão da propriedade acionária é bem expressiva, o que se explica também pela existência de mecanismos de proteção aos sócios minoritários. ${ }^{9}$

Nos primeiros, o conflito de agência se verifica entre o acionista majoritário e os demais sócios, com blocos de controle definidos diante da ausência de efetiva proteção aos investidores minoritários. Já nos segundos, a divergência ocorre entre administradores e acionistas. ${ }^{10}$ A diferenciação se explica também pela existência de duas visões relativas aos fins buscados pela empresa. Afinal, qual interesse deve prevalecer na gestão de uma companhia, o dos sócios ou dos credores que com ela contratam?

\footnotetext{
8 "Especificamente, a discussão sobre governança corporativa surgiu como resposta a diversos registros de expropriação da riqueza dos acionistas por parte dos executivos em empresas com estrutura de propriedade pulverizada e de acionistas minoritários por controladores em empresas com alta concentração acionária." SILVEIRA, Alexandre Di Miceli da. Governança corporativa no Brasil e no mundo: teoria e prática. Rio de Janeiro: Elsevier, 2010. p. 35-57.

${ }^{9}$ LAUTENSCHLEGER JÚNIOR, Nilson. Os desafios propostos pela governança corporativa ao direito empresarial brasileiro: ensaio de uma reflexão crítica e comparada. São Paulo: Malheiros Editores, 2005. p. 141.

${ }^{10}$ ROSSONI, Luciano; MACHADO-DA-SILVA, Clóvis L. Institucionalismo Organizacional e Práticas de Governança Corporativa. Revista de Administração Contemporânea, Curitiba, Edição Especial 2010. p. 6.
} 
Na busca por uma resposta definitiva, duas doutrinas foram elaboradas: a teoria da maximização da riqueza dos acionistas e a teoria do equilíbrio dos interesses dos stakeholders, neste conceito incluídos credores da sociedade, clientes, fornecedores, empregados e também os acionistas. ${ }^{11}$ Esta prioriza ganhos a longo prazo quando inclui os interesses de todo grupo que é afetado pelas atividades da empresa nos seus processos decisórios, o que pode ocasionar menor proteção aos acionistas, ao passo que aquela se fundamenta exclusivamente nos interesses dos acionistas, e justifica sua abordagem pelo fato de que se a companhia seguir uma única diretriz na tomada de decisões, alcançar os objetivos será mais fácil e todos os agentes envolvidos com a atividade da empresa vão se beneficiar mediatamente. $^{12}$

\begin{abstract}
No caso de sistemas verticais, o foco incide sobre a necessidade de os executivos atuarem de acordo com os interesses dos acionistas e não motivados por necessidade própria; em sistemas horizontais, o principal papel do conselho é defender os acionistas minoritários do oportunismo do controlador, normalmente por meio de conselheiros externos, não diretamente ligados à gestão da organização. ${ }^{13}$
\end{abstract}

Portanto, os modelos de governança corporativa seguem a tendência do mercado financeiro do país ao qual serão incorporados, atendendo às suas características e buscando solucionar os problemas mais evidentes. Possuem, contudo, um objetivo comum: legitimar a atuação dos órgãos da companhia instituindo um sistema normativo voltado para a gestão da empresa. Para isto, recomendam medidas como a arbitragem para a solução de conflitos entre sócios e entre estes e a sociedade, auditoria independente, direito de voto assegurado a todos os acionistas, distinção entre as funções do presidente do conselho (chairman) e o executivo principal $(C E O)$, formação do Conselho de Administração por membros independentes, dentre outras. ${ }^{14}$

\footnotetext{
${ }^{11}$ Wilson Kozlowski ensina que a teoria do equilíbrio dos interesses dos stakeholders é também chamada de integracionista, "pois busca a internalização dos diversos interesses relacionados com a companhia, sejam eles intra-societários (como dos minoritários) ou extra-societários (como dos trabalhadores, dos consumidores e do Estado), construindo uma organização eficiente e capaz de solucionar os diversos e co-naturais conflitos decorrentes da vida societária." (grifos do autor) KOZLOWSKI, Wilson. Breves notas de governança corporativa acerca do conflito de interesses na sociedade anônima. In: CANTIDIANO, Luiz Leonardo et al. (Org.). Governança corporativa. São Paulo: Lazuli Editora, 2005. p. 63.

${ }^{12}$ KOZLOWSKI, Wilson. Obra citada. p. 59-61.

${ }^{13}$ ROSSONI, Luciano; MACHADO-DA-SILVA, Clóvis L. Obra citada. p. 12.

${ }^{14}$ SILVA, Edson Cordeiro da. Governança corporativa nas empresas: guia prático de orientação para acionistas e conselho de administração : novo modelo de gestão para redução do custo de capital e geração de valor ao negócio. São Paulo: Atlas, 2006. p. 24-29.
} 
Com efeito, a adoção das regras de governança corporativa resulta no aumento do desempenho da empresa e na melhor captação de recursos para o financiamento dos empreendimentos. ${ }^{15}$ Edson Cordeiro da Silva bem sintetiza os efeitos advindos desta prática:

\begin{abstract}
Como uma estrutura de governança, a globalização e a necessidade de atrair capital externo demandam uniformização de práticas, as empresas passam a ser vistas como sinônimo de transparência e ética, adquirem confiança do mercado e têm suas ações mais valorizadas. Diferenciam-se de outras organizações do mesmo porte, tornam-se mais profissionais e, sem dúvida, mais valorizadas e respeitadas por toda a sua cadeia de negócios. ${ }^{16}$
\end{abstract}

Logo, percebe-se que a lógica por trás da governança corporativa se firma no sentido de proporcionar aos proprietários da sociedade, acionistas detentores de parcelas do capital social, mecanismos de fiscalização e controle da atuação dos membros da companhia incumbidos de gerir os investimentos e criar oportunidades de desenvolvimento e crescimento da atividade empresarial, banindo das relações negociais quaisquer manifestações de oportunismo e prevalência de interesses particulares.

\title{
2.2 Valores centrais de governança
}

A despeito da existência de diversos códigos de boas práticas de governança adaptados às características do mercado financeiro de cada país, atendendo às necessidades de sua cultura empresarial, alguns valores norteadores devem ser observados sob pena de se descaracterizar os objetivos principais da governança corporativa.

\footnotetext{
15 "Diga-se, inclusive, que, numa economia globalizada, em que os mercados disputam recursos dos investidores - internamente, com as demais opções de investimentos ofertadas ao público e, externamente, em competição com os mercados dos outros países -, a boa governança acaba por se constituir em fator determinante para a atração de investidores pelos países em desenvolvimento - que tanto deles necessitam ante um nível interno de poupança, em geral, baixo -, ficando a depender de sua qualidade o tipo de investimento captado.” MILLER, Daniel Schiavon. Governança corporativa e full disclosure: o direito à informação como direito subjetivo instrumental, implicitamente essencial e irrevogável do acionista. In: CANTIDIANO, Luiz Leonardo et al. (Org.). Governança corporativa.São Paulo: Lazuli Editora, 2005. p. 92.

${ }^{16}$ SILVA, Edson Cordeiro da. Governança corporativa nas empresas: guia prático de orientação para acionistas e conselho de administração : novo modelo de gestão para redução do custo de capital e geração de valor ao negócio. São Paulo: Atlas, 2006. p. 136.
} 
Sustentam as práticas de estruturação dos órgãos da alta gestão empresarial e a conduta de seus agentes os valores da transparência das informações, a prestação de contas, a conformidade com as normas reguladoras e o senso de justiça. Todos estes valores impõem um padrão de conduta aos agentes corporativos, no sentido de exigir que estes apliquem tais conceitos no seu ambiente funcional.

É dizer, a transparência (disclosure) determina a ampla divulgação das informações relacionadas aos negócios da empresa, permitindo aos acionistas a adequada avaliação do desempenho de seus gestores na consecução dos objetivos corporativos, com a visão futura de grandes retornos ao investimento aplicado, bem como possibilita a apresentação de um panorama de informações relevantes para o direcionamento das decisões tomadas pelos órgãos deliberativos da companhia. ${ }^{17}$

Neste mesmo sentido, a prestação de contas (accountability) sustenta o fornecimento de dados de auditoria correspondentes à realidade da companhia, isto é, o panorama contábil de sua atuação. ${ }^{18}$

A observância às disposições normativas (o estatuto social da companhia, regulamentos, códigos internos de governança corporativa e leis no âmbito nacional), ou compliance, indica a adoção, por parte da empresa, de condutas legitimadas juridicamente, o que facilita a verificação de comportamentos que não se encaixem nos adequados padrões corporativos. $^{19}$

E, finalmente, a equidade ou o senso de justiça (fairness), como fundamento legal das normas de governança corporativa, de onde derivam os outros princípios, consubstanciado no tratamento igualitário garantido aos acionistas majoritários e minoritários (bem como, gradativamente, de outras partes interessadas, os stakeholders $).{ }^{20}$

Sob este aspecto, é possível perceber a noção de justiça distributiva embutida nas razões que deram surgimento aos mecanismos de governança corporativa, que impedem a expropriação de poder por parte dos gestores e dos acionistas controladores e afastam a

\footnotetext{
${ }^{17}$ MILLER, Daniel Schiavon. Governança corporativa e full disclosure: o direito à informação como direito subjetivo instrumental, implicitamente essencial e irrevogável do acionista. In: CANTIDIANO, Luiz Leonardo et al. (Org.). Governança corporativa.São Paulo: Lazuli Editora, 2005. p. 91.

${ }^{18}$ The OECD Principles of Corporate Governance. Disponível em: <http://www.oecd.org>. Acesso em: 13/01/2013.

${ }^{19}$ The OECD Principles of Corporate Governance.

${ }^{20}$ The OECD Principles of Corporate Governance.
} 
ocorrência de escândalos empresariais envolvendo a manipulação de dados contábeis e outras informações. $^{21}$

Os padrões de conduta impostos pelas regras de governança corporativa, portanto, visam ao estabelecimento de um equilíbrio nas relações negociais dentro da estrutura das companhias, como forma de favorecer a participação de acionistas e investidores nos empreendimentos por eles financiados. Para tanto, é crucial que gestores e agentes corporativos, especialmente aqueles envolvidos com a alta gestão das companhias, órgãos representativos e deliberativos, adotem comportamentos socialmente aceitos, moralmente desejáveis e juridicamente estabelecidos, o que remete a discussão para o campo da fiscalização das relações negociais, cuja fundamentação reside na exigência de condutas guiadas pela boa-fé objetiva, princípio informador dos valores de governança corporativa.

\section{A BOA-FÉ OBJETIVA COMO LIMITE PARA A ATUAÇÃo DOS ADMINISTRADORES}

Na esteira da doutrina de Arnoldo Wald, a adoção das regras de governança corporativa por uma companhia implica na instituição do Estado de Direito como modelo jurídico-normativo regulador da dinâmica empresarial, na medida em que estabelece limites funcionais à atuação dos órgãos da sociedade, mormente o Conselho de Administração e a Diretoria, ao mesmo tempo em que inaugura um "sistema de freios e contrapesos entre os órgãos societários". ${ }^{22}$

De fato, os valores centrais que norteiam as regras de governança corporativa indicam a existência de um padrão comportamental apontado como ideal e necessário, dirigido aos membros da companhia, especialmente diretores e administradores: o dever de agir de acordo com a boa-fé.

Instituto que remonta ao direito romano, a boa-fé figura atualmente como princípio basilar da ordem jurídica privada, com incidência no Direito de Família, Direito das Coisas, e

${ }^{21}$ ROSSONI, Luciano; MACHADO-DA-SILVA, Clóvis L. Institucionalismo Organizacional e Práticas de Governança Corporativa. Revista de Administração Contemporânea, Curitiba, Edição Especial 2010. p. 7.

22 WALD, Arnoldo. O governo das empresas. In: WALD, Arnoldo (Org.). Doutrinas essenciais: volume 3: direito empresarial : sociedade anônima. São Paulo: Revista dos Tribunais, 2011. p. 326. 
nas relações obrigacionais e empresariais. ${ }^{23}$ Não obstante o valor histórico atribuído ao instituto, a moderna aplicação da boa-fé tem como fundamento a ampliação do dirigismo contratual, cuja atuação foi incisiva na delimitação de novos contornos jurídicos para o alcance da autonomia privada, como bem salienta Ricardo Lupion:

\footnotetext{
$\mathrm{O}$ individualismo adaptou-se à realidade do século XX, levando à relativização do contrato e o direito dos contratos, em face da nova realidade econômica, política e social ganha uma nova função, qual seja, a de procurar a realização da justiça e do equilíbrio contratual. $^{24}$
}

Sabe-se que a boa-fé se desdobra em dois fundamentos, um cujo caráter é subjetivo, e o outro com natureza objetiva. A boa-fé subjetiva parte da perspectiva do indivíduo para trazer ao campo jurídico a situação na qual alguém ignora algum fato. É, assim, um estado de espírito que revela o desconhecimento de um sujeito em determinada situação. A boa-fé objetiva, distintamente, parte da perspectiva de uma posição jurídica ocupada por alguém em determinada situação, e impõe a esta pessoa que aja de acordo com a posição que ocupa. ${ }^{25}$ Consiste esta última, portanto, na exigência de padrões de conduta a serem observados no meio das relações privadas. ${ }^{26}$

Assim, representa este seguimento da boa-fé um padrão objetivo de comportamento, o elemento essencial que deve figurar como norteador da conduta das partes envolvidas em uma relação negocial, aqui abrangidas desde as obrigações habituais que são celebradas cotidianamente até complexos contratos empresariais pactuados por multinacionais.

Neste sentido, a estruturação da boa-fé objetiva se pauta em parâmetros consolidados socialmente e abarcados pela tutela jurídica, pois capazes de ensejar consequências de toda ordem nas relações econômicas. Fala-se então no dever de agir com lealdade aos termos acordados, a fim de realizar a obrigação estabelecida sem frustrar a confiança despendida pela outra parte.

${ }^{23}$ CORDEIRO, Antônio Manuel da Rocha e Menezes. Da boa fé no direito civil. Coimbra: Almedina, 2007. p. 18.

${ }^{24}$ LUPION, Ricardo. Boa fé objetiva nos contratos empresariais: contornos dogmáticos dos deveres de conduta. Porto Alegre: Livraria do Advogado, 2011. p. 30.

${ }^{25}$ CORDEIRO, Antônio Manuel da Rocha e Menezes. Obra citada. p. 317.

26 "A boa-fé se apresenta como uma exigência de lealdade, modelo objetivo de conduta, arquétipo social pelo qual impõe o dever-poder de que cada pessoa ajuste a própria conduta a esse modelo, agindo como agiria uma pessoa honesta, escorreita e leal". STJ. Resp n ${ }^{\circ}$ 981.750-MG, $3^{\text {a }}$ Turma, j. em 13/04/2010, rel. Min. Nancy Andrighi. Disponível em: <HTTP://www.stj.gov.br>. Acesso em: $07 / 02 / 2013$. 
No caminho pela concretização da obrigação pactuada, pode-se vislumbrar, à luz dos preceitos que informam a boa-fé objetiva, deveres anexos que substancializam, tornam viável o cumprimento legítimo de uma posição jurídica. É o que se depreende da lição de Judith Martins-Costa, quando sintetiza tais deveres como sendo o cuidado, a previdência e a segurança, o aviso e o esclarecimento, a informação e a prestação de contas, colaboração e cooperação, proteção e cuidado com a pessoa e o patrimônio da contraparte, omissão e segredo. ${ }^{27}$ A melhor doutrina define estes deveres como laterais, anexos ao dever de prestar a obrigação principal e, por isto, decorrentes da aplicação da boa-fé objetiva em casos concretos.

Em verdade, pode-se afirmar que a equivalência entre os deveres anexos decorrentes da função criadora da boa-fé objetiva e os valores das regras de governança corporativa, que inspiram a elaboração de diversos códigos de boas práticas pelo mundo, indica esta mesma boa-fé como a fonte legitimadora do sistema de governança. ${ }^{28}$ É dizer, considerando-se fairness, accountability e disclosure, que possuem correspondência com os deveres laterais já referidos, torna-se evidente que a origem e fundamentação das regras de governança corporativa residem justamente na aplicação da boa-fé objetiva, cuja incidência se justifica para solucionar os conflitos de agência decorrentes da separação entre propriedade e controle.

No âmbito do direito corporativo, o que se verifica nas regras ditadas pelo governo da empresa ${ }^{29}$ é exatamente esta tendência de atribuir aos administradores o dever de agir em consonância bom a boa-fé objetiva, em virtude do cargo que ocupam e da função representativa que exercem, no âmbito de uma relação fiduciária, e correspondente à ampliação de seus deveres funcionais dentro da companhia. ${ }^{30}$

27 MARTINS-COSTA, Judith. A boa-fé no direito privado: sistema e tópica no processo obrigacional. São Paulo: Revista dos Tribunais, 2000. p. 439.

28 "O regime jurídico do governo da empresa busca definir os poderes e as garantias dadas aos integrantes da entidade, visando ao funcionamento eficiente da estrutura societária e à atuação dos agentes conforme o princípio geral da boa-fé e a ética". WALD, Arnoldo. Obra citada, p. 309.

${ }^{29}$ Expressão cunhada por Arnoldo Wald para designar governança corporativa. "Entendemos que, no direito brasileiro, descabe caracterizar a sociedade anônima como corporação, tratando-se de um anglicismo condenável, não só por respeito à língua nacional como também pela associação de ideias que pode acarretar. Na língua portuguesa, corporação tem o sentido de associação profissional, sendo inclusive uma reminiscência medieval." E continua o autor: "Além disso, a palavra governança não nos parece a mais adequada, já que nos referimos ao governo da sociedade, numa situação paralela ao estudo que se faz, em direito público, do governo de um país, seja ele democrático ou totalitário." WALD, Arnoldo. Obra citada. p. 309.

${ }^{30}$ Dentre as funções do Conselho de Administração estabelecidas pelo art. 142 da Lei no 6.404/1976, Lei das Sociedades por Ações, destacam-se a escolha e destituição dos auditores independentes, a deliberação sobre a emissão de ações ou bônus de subscrição, a manifestação sobre o relatório da administração e as contas da diretoria, a fiscalização da gestão dos diretores e a orientação geral dos negócios da companhia. 
De fato, o Conselho de Administração é o órgão da companhia que possibilita a efetiva interação entre os acionistas e a gestão da empresa, uma vez que suas atribuições abordam a tomada de decisões estratégicas e o acompanhamento do órgão executivo, a Diretoria, com vistas a propiciar os melhores retornos ao patrimônio investido pelos sócios. ${ }^{31}$

A relação entre os administradores e os acionistas consiste, assim, numa relação fiduciária, característica do relacionamento de agência, definido por Jensen e Meckling como um contrato firmado entre o principal, beneficiário, e o agente, o gestor que, autorizado pelo primeiro, vai desempenhar atividades em seu favor. ${ }^{32}$ Envolve, portanto, os deveres de cuidado, lealdade e transparência.

Não por acaso, a Lei das Sociedades por Ações determina o direcionamento das condutas dos administradores segundo os deveres de diligência, lealdade e informação. $O$ primeiro consiste na probidade e cuidado empregados no exercício de suas funções. $\mathrm{O}$ segundo refere-se à consecução dos fins da companhia e de seus acionistas: é a realização estrita da obrigação que lhe foi incumbida. E, por fim, o dever de informar aos acionistas tudo o quanto for relevante e atinente aos negócios da empresa. ${ }^{33}$

Como se percebe, estes deveres impostos pela Lei $\mathrm{n}^{\circ}$ 6.404/76, também dispostos nos mais variados códigos de boas práticas de governança corporativa, apresentam completa correspondência com os preceitos decorrentes da aplicação da boa-fé objetiva. ${ }^{34}$ Estas determinações visam tutelar o interesse das partes quando inseridas em um ambiente negocial, no caso, os acionistas. Criam, portanto, condições para a execução do contrato, ainda que fictício, entre administrador e acionista, o qual possui, na boa-fé objetiva, a proteção de seus interesses em face de possíveis arbítrios de seu gestor.

\footnotetext{
${ }^{31}$ SILVEIRA, Alexandre Di Miceli da. Obra citada, p. 258.

32 "We define an agency relationship as a contract under which one or more persons (the principal (s)) engage another person (the agent) to perform some service on their behalf which involves delegating some decision making authority to the agent." JENSEN, Michael; MECKLING, William. Theory of the Firm: Managerial Behavior, Agency Costs and Ownership Strcture. Journal of Financial Economics, v. 3, out. 1976. p. 305-360.

${ }^{33}$ Lei $\mathrm{n}^{\circ} 6.404$, de 15 de dezembro de 1976, art. 153 a 157.

${ }^{34}$ Assim é a doutrina de Judith Martins-Costa: "Permite tal princípio a identificação concreta de novos deveres, que não estão expressos no contrato nem nascem de disposição legislativa pontual, os já aludidos deveres avoluntaristas e instrumentais que envolvem todo o desenrolar da relação, a globalidade dos interesses envolvidos. (...) Diversa e maior é a intensidade dos deveres decorrentes da boa-fé quando os interesses em jogo não são contrapostos, como acontece nos contratos bilaterais, mas quando se verifica uma atividade em proveito alheio: nos acordos de gestão, nos negócios fiduciários em geral o dever de levar em conta o interesse da outra parte (tua res agitur) é o conteúdo do dever do gestor ou do fiduciário." MARTINS-COSTA, Judith. Mercado e solidariedade social entre cosmos e taxis: a boa-fé nas relações de consumo. In: MARTINS-COSTA, Judith. A reconstrução do direito privado: reflexos dos princípios, diretrizes e direitos fundamentais constitucionais no direito privado. São Paulo: Revista dos Tribunais, 2002. p. 240.
} 
Não obstante, a teoria da firma ${ }^{35}$, sob a ótica jurídica, também se presta a fundamentar a obrigação dos administradores de dirigirem sua conduta à luz da boa-fé objetiva, bem como as implicações daí decorrentes. De maneira geral, esta teoria indica um conjunto de contratos como fato hipotético formador da estrutura empresarial, negócios jurídicos múltiplos e conexos que vinculam partes afetadas pela atuação corporativa. Porém, diante do infinito número de circunstâncias impossíveis de serem previstas pelo contrato, aos agentes executivos é concedido o direito de controle residual, isto é, o direito de direcionar os negócios segundo sua vontade. ${ }^{36}$

Tendo em vista que da aplicação da boa-fé objetiva decorre também a sua função hermenêutica ${ }^{37}$, o contrato fictício celebrado entre executivos e acionistas só pode ser interpretado à luz deste princípio, que vincula a atuação dos administradores à busca pelo melhor retorno ao investimento aplicado pelos reais proprietários da companhia. Disto sucedem duas implicações jurídicas, quais sejam, a responsabilização dos administradores por descumprimentos dos deveres de conduta impostos pela boa-fé objetiva e a ampliação da proteção aos acionistas, que, em contrapartida, possuem o direito de fiscalizar os atos de seus gestores e exigir-lhes não só a prestação obrigacional, como também sua adequada execução pautada pela confiança, lealdade, transparência.

A responsabilização dos administradores pela quebra dos deveres de conduta deve ser apurada objetivamente, isto é, ainda que este tenha agido sem culpa, como consequência da obrigação de se observar os preceitos da boa-fé objetiva. Embora o ordenamento jurídico estipule a responsabilidade subjetiva, cuja apuração depende da verificação da culpa do agente, a letra do parágrafo único do art. 927 do Código Civil de 2002: "Haverá obrigação de reparar o dano, independentemente de culpa, nos casos especificados em lei, ou quando a atividade normalmente desenvolvida pelo autor do dano implicar, por sua natureza, risco para os direitos de outrem."

\footnotetext{
${ }^{35}$ Conferir: COASE, Ronald. The Nature of the Firm. Economica, v. 4, p. 386-405, 1937. ALCHIAN, Armen; DEMSETZ, Harold. Production, information costs and economic organization. American Economic Review, v. 62, p. 777-795, 1972. FAMA, Eugene; JENSEN, Michael. Separation of ownership and control. Journal of Law and Economics, v. 26, p. 301-327, jun. 1983.

${ }^{36}$ SILVEIRA, Alexandre Di Miceli da. Obra citada, p. 37.

37 "É reconhecida à boa-fé objetiva as funções hermenêutica e integradora, fonte de deveres jurídicos e limite ao exercício de direitos subjetivos." MARTINS-COSTA, Judith. Mercado e solidariedade social entre cosmos e taxis: a boa-fé nas relações de consumo. In: MARTINS-COSTA, Judith. A reconstrução do direito privado: reflexos dos princípios, diretrizes e direitos fundamentais constitucionais no direito privado. São Paulo: Revista dos Tribunais, 2002. p. 245.
} 
Ora, a atividade desempenhada pelos administradores é capaz de ocasionar danos aos direitos de propriedade dos acionistas, que podem se ver privados dos reais resultados de seu investimento, especialmente se considerada no contexto de um cenário econômico instável. Ademais, a técnica e a especialidade exigidas pelo cargo reforçam a necessidade de se atribuir ao administrador da companhia a responsabilidade objetiva, quer por seus atos sem culpa quer pelos atos dos diretores, solidariamente com estes, já que uma das funções estabelecidas em lei para o Conselho de Administração é fiscalizar a atuação da Diretoria.

Da fundamentação da governança corporativa no princípio da boa-fé objetiva decorre também a sua função restritiva de direitos em virtude da posição que ocupa o sujeito em determinada relação jurídica. ${ }^{38}$ Assim, aos administradores, além da atribuição de condutas positivas, isto é, comissivas, também são impostas condutas negativas, as quais obrigam a omissão por aqueles agentes. Aqui, pode-se citar a vedação à divulgação de informações sigilosas da companhia que ainda não se tornaram públicas, bem como a proibição de contratar com a empresa em benefício próprio ou de terceiros. ${ }^{39}$

Consequência disto para os acionistas, os imediatamente interessados no desenvolvimento da empresa, é a garantia do respeito aos direitos inerentes à condição de sócio de uma companhia aberta que internalizou regras de governança corporativa na estruturação de seu sistema normativo, como a equidade no tratamento de majoritários e minoritários e o amplo acesso às informações referentes aos negócios da empresa (full disclousure, ou total transparência na divulgação das informações). Estes, entre outros, são direitos atribuídos aos sócios no momento em que se tornam proprietários de uma parcela do capital social, tenha ela valor expressivo ou não, porquanto não existe tal diferenciação.

Diferentemente do que restou até aqui exposto é o entendimento extraído de alguns julgados da Suprema Corte de Delaware, nos Estados Unidos, cuja tendência há muito vem no sentido de aceitar a criação de um dever autônomo, ao lado dos deveres de cuidado e lealdade, consubstanciado na boa-fé. ${ }^{40}$

A doutrina norte-americana aponta o surgimento de mudanças socioeconômicas no âmbito corporativo como circunstância que exigiu a criação de novos deveres face aos anteriormente existentes, como forma de reajustar a nova realidade do mercado. Surgem então

\footnotetext{
38 "A boa-fé atua, assim, como norma que não admite condutas que contrariem o mandamento de agir com lealdade e correção, o que afasta o exercício abusivo de posições jurídicas, notadamente no âmbito contratual." MARTINS-COSTA, Judith. Obra citada. p. 249.

${ }^{39}$ Lei $\mathrm{n}^{\circ} 6.404$, de 15 de dezembro de 1976, art. 155 e 156.

${ }^{40}$ EISENBERG, Melvin A. The Duty of Good Faith in Corporate Law. Delaware Journal of Corporate Law, Vol. 3, No. 1, 2005. Disponível em: <http://www.ssrn.com/abstract=899212>. Acesso em: 20/02/2013.
} 
as primeiras referências à boa-fé (duty of good faith) no meio corporativo. No entanto, os precedentes parecem não considerar tal princípio como gerador dos deveres de lealdade, cuidado e informação, como analisado supra.

$\mathrm{Na}$ verdade, classificam a boa-fé como um dever autônomo, criado em virtude do limitado alcance dos tradicionais deveres fiduciários (loyalty, duty of care), o que resultava na ausência de regulamentação de determinadas situações frente às condutas dos administradores. Ademais, a Corte se inclina a considerar a boa-fé subjetiva como requisito para a responsabilização dos executivos ${ }^{41}$, posição divergente à deste trabalho, pois, como restou exposto, não basta que o administrador acredite estar agindo corretamente em observância às normas estatutárias: é necessário que este dirija sua conduta estritamente de acordo com a boa-fé objetiva, possibilitando aos acionistas o amplo acesso às informações da empresa, tratamento igualitário, transparência nos dados da contabilidade.

Sendo uma relação contratual que envolve características fiduciárias, onde se verifica uma figura que deve realizar determinadas funções em benefício de outrem, não há dúvidas de que a boa-fé objetiva deve ser o marco regulatório desta situação jurídica, impondo os deveres de conduta anexos à sua incidência e ensejando a responsabilização daquele que frustra tanto a prestação obrigacional principal quanto suas formas de execução, isto é, com lealdade, diligência, transparência de informações, equidade.

Pode-se dizer, portanto, que o dever de agir de acordo com a boa-fé objetiva não é autônomo às demais obrigações impostas aos administradores das companhias, mas consiste, em verdade, no fundamento jurídico de institucionalização ${ }^{42}$ das regras de governança corporativa nas empresas, porquanto dirige a conduta dos executivos para a realização dos fins dos acionistas e do empreendimento, exigindo posturas íntegras favoráveis à manutenção da confiança entre as partes e a harmonia entre a ética e os negócios empresariais.

\footnotetext{
${ }^{41}$ BAINBRIDGE, Stephen M.; LOPES, Star; OKLAN, Benjamin. The convergence of Good Faith and Oversight. UCLA School of Law. Law-Econ Research Paper No. 07-09. Disponível em: <http://www.ssrn.com/abstract=1006097>. Acesso em: 25/01/2013. STRINE, Leo E.; HAMERMESH, Lawrence A.; BALOTTI, R. Franklin; GORRIS, Jeffrey M. Loyalty's Core Demand: the defining role of good faith in corporation law (February 26, 2009). Harvard Law and Economics Discussion Paper $n^{\circ}$ 630. Disponível em:<http://ssrn.com/abstract=1349971>. Acesso em: 20/02/2013.

${ }^{42}$ Tolbert e Zucker, citados por Rossoni e Machado-da-Silva, definem institucionalização como "o processo por meio do qual os componentes da estrutura formal se tornam amplamente aceitos, necessários e apropriados, servindo para legitimar as organizações." ROSSONI, Luciano; MACHADO-DA-SILVA, Clóvis L. Obra citada. p. 16.
} 


\section{PERSPECTIVAS DO BRASIL}

O histórico do mercado de capitais brasileiro revela o predomínio de blocos de controle na estrutura da propriedade acionária do país. Até a década de 1960 o mercado era fortemente controlado pelo governo ao mesmo tempo em que a abertura da economia se apresentava pouco expressiva. Após o golpe militar de 1964, alguns fatores como a criação do Conselho Monetário Nacional e do Banco Central, ao lado, posteriormente, da criação da Comissão de Valores Mobiliários, possibilitaram a abertura e o desenvolvimento do mercado de capitais do país. ${ }^{43}$

A transição política dos fins da década de 80 e início da década de 90 e combinada com a quebra de barreiras ao ingresso de capitais estrangeiros no país, a desestatização e as reformas econômicas auxiliaram na mudança do cenário nacional e no processo de privatização. $^{44}$

A criação dos segmentos de listagem da Bovespa (Níveis 1 e 2 e o Novo Mercado), em dezembro de 2000, contribuiu fortemente para o crescimento do mercado com a imposição de regras de governança corporativa com foco especial na transparência das informações e na proteção dos acionistas minoritários, como forma de repassar segurança aos investidores. $^{45}$

O Novo Mercado, cuja inspiração vem da prática alemã (Neuer Markt), e os Níveis 1 e 2 foram criados com o objetivo de mostrar ao mercado as empresas que se preocupam com a fiscalização dos atos da sua administração e a extensão dos direitos dos acionistas, controladores ou não. Como explicam Rosseti e Andradre:

\footnotetext{
${ }^{43}$ SILVEIRA, Alexandre Di Miceli da. Governança corporativa no Brasil e no mundo: teoria e prática. Rio de Janeiro: Elsevier, 2010. p. 176-179.

44 " $O$ interesse despertado pelas privatizações e concessões, que também começaram a se desenvolver naquela época, a necessidade de novos e importantes investimentos na infraestrutura, as posteriores reformas constitucionais, que deram novo tratamento ao capital estrangeiro, a modernização das Bolsas e a atuação construtiva da CVM fizeram com que, com o decorrer do tempo, o sucesso obtido no mercado de capitais ensejasse também a vinda de investimentos mais duradouros direcionados a novos setores de atividades ou às operações de fusões e aquisições." WALD, Arnoldo. Dez anos de capital estrangeiro no mercado de capitais. In: WALD, Arnoldo (Org.). Doutrinas essenciais: volume 8; direito empresarial: mercado de capitais. São Paulo: Revista dos Tribunais, 2011. p. 383387.

${ }^{45}$ SANTANA, Maria Helena dos Santos Fernandes; GUIMARÃES, Juliana Paiva. Mercado de Valores Mobiliários: evolução recente e tendências. In: WALD, Arnoldo (Org.). Doutrinas essenciais: volume 8; direito empresarial: mercado de capitais. São Paulo: Revista dos Tribunais, 2011. p. 487.
} 
nesses novos segmentos, a adesão às práticas diferenciadas de governança corporativa é voluntária e implica a assinatura de um contrato de adesão envolvendo os controladores, os administradores (Conselho de Administração e Diretoria Executiva) e a bolsa. ${ }^{46}$

A assinatura do referido contrato, classificado como contrato de adesão porque celebrado através da aceitação de uma parte às cláusulas estabelecidas unilateralmente pela outra $^{47}$, reforça a incidência do princípio da boa-fé objetiva na regulação e interpretação de suas cláusulas, obrigando aos administradores a sua completa observância, em conjunto com os deveres anexos de conduta e as restrições de direitos decorrentes de sua aplicação.

Os segmentos de listagem criados pela Bovespa exigem regras de governança corporativa e a possibilidade de uma companhia migrar para outra listagem. O Nível 1 exige, dentre outras condições, a dispersão do capital, disclosure, acordos de acionistas, reunião pública. O Nível 2 engloba as exigências do Nível 1 e adiciona o direito de voto aos acionistas preferenciais, a instituição de arbitragem para solução dos conflitos empresariais, Conselho de Administração, tag along, dentre outras recomendações. O Novo Mercado abrange as regras dos outros dois segmentos e acrescenta a exigência de emissão exclusiva de ações ordinárias. $^{48}$

Estudos revelam significativos avanços na adoção das regras de governança corporativa pelas companhias brasileiras, o que pode ser apontado como causa do processo de dispersão da propriedade acionária que vem ocorrendo no mercado de capitais, principalmente se for considerado o fato de que o regime de proteção aos investidores influencia sobremaneira a imagem da empresa diante dos possíveis clientes. ${ }^{49}$

46 ROSSETTI, José Paschoal; ANDRADE, Adriana. Governança corporativa: fundamentos, desenvolvimento e tendências. 5. ed. atual. e ampl. São Paulo: Atlas, 2011. p. 444.

${ }^{47}$ Segundo a doutrina de César Fiuza: "contrato de adesão é aquele que se celebra pela aceitação de uma das partes de cláusulas contratuais gerais propostas pela outra, a fim de constituir a totalidade ou, ao menos, a porção substancial do conteúdo de sua relação jurídica. (...) é de adesão, referindo-se exatamente ao modo de uma das partes expressar o consentimento, que se dá por simples adesão a um conjunto de cláusulas propostas pela outra parte." FIUZA, César. Contratos. Belo Horizonte: Del Rey, 2010. p. 147.

${ }^{48}$ Conferir: <http://www.bmfbovespa.com.br>.

${ }^{49}$ Conferir: Panorama da Governança Corporativa no Brasil, 2010. Instituto Brasileiro de Governança Corporativa. Disponível em: $<$ http://www.ibgc.org.br $>$. Acesso em: 17/04/2013. "Our findings show that, together with ownership structure, legal systems and their related corporate law, the development and structure of capital, and the political and economic institutions help to constitute the myriad of varieties of capitalisms that characterize corporate governance systems in the emerging economies." AGUILERA, Ruth V.; KABBACH-CASTRO, Luiz Ricardo; LEE, Jun Ho; YOU, Jihae. Corporate Governance in emerging markets (March 12, 2012). CAPITALISMS AND CAPITALISM IN THE $21^{\text {ST }}$ CENTURY. G. Morgan ans R. Whitley, Eds., Oxford University Press, 2012. Disponível em: <http://www.ssrn.com/abstract=1806525>. Acesso em: 20/05/2013. 
Pesquisa realizada pelo Instituto Brasileiro de Governança Corporativa identificou como benefícios da adoção dessas práticas o alinhamento entre acionistas e executivos, o aprimoramento da transparência e o desenvolvimento da gestão, assim como a melhor imagem da empresa e o fácil acesso ao capital. A pesquisa aponta também o desenvolvimento de políticas de proteção aos sócios minoritários, por parte das companhias, como o tag along e a escolha da maioria dos membros que irá compor o Conselho Fiscal por acionistas não controladores, bem como a maior presença de conselheiros independentes na composição do Conselho de Administração. ${ }^{50}$

Apesar dos inegáveis avanços, forçoso concluir que o mercado de capitais brasileiro precisa consolidar as práticas de governança corporativa para garantir aos investidores segurança e transparência para ingressarem nos empreendimentos que, mediatamente, refletem no desenvolvimento econômico do país e nos demais âmbitos da vida em sociedade, especialmente se o foco for quebrar o padrão de predomínio da concentração da propriedade com sócios que detém mais da metade do capital social da empresa.

\section{CONCLUSÃO}

Os conflitos decorrentes da separação entre a propriedade e o controle das empresas e a consequente crise da legitimação das condutas e decisões tomadas pelos executivos figuram como o foco da razão das regras de governança corporativa.

Porém, esta legitimação somente é possível se a condução das atribuições daqueles agentes for pautada pelo princípio da boa-fé objetiva, cuja função é garantir aos acionistas a proteção de seus direitos de propriedade através da imposição de deveres anexos de conduta aos administradores, correspondentes aos princípios gerais de governança corporativa.

Assim, só serão legítimas e aplicáveis as decisões, os atos e quaisquer outras manifestações advindas da alta gestão da sociedade, se estiverem respaldadas pelos limites da boa-fé objetiva, que se justifica em razão da relação fiduciária estabelecida entre gestor e principal e de sua natureza contratual.

\footnotetext{
${ }^{50}$ Resultados como o aprimoramento das relações entre controladores e minoritários, tendo se tornado intensa e colaborativa, com maior participação daqueles nos assuntos corporativos. Panorama da Governança Corporativa no Brasil, 2010. Instituto Brasileiro de Governança Corporativa. Disponível em:<http://www.ibgc.org.br>. Acesso em: 17/04/2013.
} 
Além disto, a incidência da boa-fé subjetiva não bastaria para legitimar as condutas dos administradores, porquanto esta se verifica no âmbito da consciência do sujeito, aquilo que ele acredita corresponder ao certo. Sendo assim, é necessário que a boa-fé objetiva estabeleça uma ligação com o conjunto de regras de conduta dominantes em determinado agrupamento social, razão pela qual a imposição desta obrigação aos administradores corresponde aos anseios dos proprietários acionistas.

Ademais, a institucionalização das práticas de governança resulta no equilíbrio de forças dentro da companhia ao atribuir aos órgãos da alta gestão limitações funcionais no intuito de proteger a persecução dos fins da empresa e garantir os direitos dos sócios.

As práticas de governança no Brasil têm capacidade para modificar o cenário da distribuição acionária no país e ensejar a adoção, por parte das companhias, dos valores que norteiam o princípio da boa-fé objetiva e que estão inseridos na fundamentação das regras do governo da empresa, possibilitando o aproveitamento que os benefícios de uma gestão responsável é capaz de fornecer a toda uma economia.

\section{REFERÊNCIAS}

AGUILERA, Ruth V.; KABBACH-CASTRO, Luiz Ricardo; LEE, Jun Ho; YOU, Jihae. Corporate Governance in emerging markets (March 12, 2012). CAPITALISMS AND CAPITALISM IN THE 21 ${ }^{\text {ST }}$ CENTURY. G. Morgan and R. Whitley, Eds., Oxford University Press, 2012. Disponível em: <http://www.ssrn.com/abstract=1806525>. Acesso em: 20/05/2013.

BAINBRIDGE, Stephen M.; LOPES, Star; OKLAN, Benjamin. The convergence of Good Faith and Oversight. UCLA School of Law. Law-Econ Research Paper No. 07-09. Disponível em: <http://www.ssrn.com/abstract=1006097>. Acesso em: 25/01/2013.

CANTIDIANO, Luiz Leonardo et al. (Org.). Governança corporativa.São Paulo: Lazuli Editora, 2005.

CORDEIRO, Antônio Manuel da Rocha e Menezes. Da boa fé no direito civil. Coimbra: Almedina, 2007.

EISENBERG, Melvin A. The Duty of Good Faith in Corporate Law. Delaware Journal of Corporate Law, Vol. 3, No. 1, 2005. Disponível em: <http://www.ssrn.com/abstract=899212>. Acesso em: 20/02/2013.

INSTITUTO BRAISLEIRO DE GOVERNANÇA CORPORATIVA. Panorama da Governança Corporativa no Brasil, 2010. Disponível em: $\langle$ http://www.ibgc.org.br $>$. Acesso em: 17/04/2013. 
JENSEN, Michael; MECKLING, William. Theory of the Firm: Managerial Behavior, Agency Costs and Ownership Strcture. Journal of Financial Economics, v. 3, out. 1976.

LAUTENSCHLEGER JÚNIOR, Nilson. Os desafios propostos pela governança corporativa ao direito empresarial brasileiro: ensaio de uma reflexão crítica e comparada. São Paulo: Malheiros Editores, 2005.

LUPION, Ricardo. Boa fé objetiva nos contratos empresariais: contornos dogmáticos dos deveres de conduta. Porto Alegre: Livraria do Advogado, 2011.

MARTINS-COSTA, Judith. A boa-fé no direito privado: sistema e tópica no processo obrigacional. São Paulo: Revista dos Tribunais, 2000.

MARTINS-COSTA, Judith. A reconstrução do direito privado: reflexos dos princípios, diretrizes e direitos fundamentais constitucionais no direito privado. São Paulo: Revista dos Tribunais, 2002.

ORGANISATION FOR ECONOMIC CO-OPERATION AND DEVELOPMENT (OECD). The OECD Principles of Corporate Governance. Disponível em: 〈http://www.oecd.org>. Acesso em: 13/01/2013.

PARGENDLER, Mariana. State ownership and corporate governance (May, 1, 2012). Firdham Law Review, vol. 80, No. 6, 2012. Disponível em: <http://ssrn.com/abstract=1854452>. Acesso em: 25/05/2013.

ROSSETTI, José Paschoal; ANDRADE, Adriana. Governança corporativa: fundamentos, desenvolvimento e tendências. 5. ed. atual. e ampl. São Paulo: Atlas, 2011.

ROSSONI, Luciano; MACHADO-DA-SILVA, Clóvis L. Institucionalismo Organizacional e Práticas de Governança Corporativa. Revista de Administração Contemporânea, Curitiba, Edição Especial 2010.

SANTANA, Maria Helena dos Santos Fernandes; GUIMARÃES, Juliana Paiva. Mercado de Valores Mobiliários: evolução recente e tendências. In: WALD, Arnoldo (Org.). Doutrinas essenciais: volume 8; direito empresarial: mercado de capitais. São Paulo: Revista dos Tribunais, 2011.

SILVA, Edson Cordeiro da. Governança corporativa nas empresas: guia prático de orientação para acionistas e conselho de administração : novo modelo de gestão para redução do custo de capital e geração de valor ao negócio. São Paulo: Atlas, 2006.

SILVEIRA, Alexandre Di Miceli da. Governança corporativa no Brasil e no mundo: teoria e prática. Rio de Janeiro: Elsevier, 2010.

STRINE, Leo E.; HAMERMESH, Lawrence A.; BALOTTI, R. Franklin; GORRIS, Jeffrey M. Loyalty's Core Demand: the defining role of good faith in corporation law (February 26, 2009). Harvard Law and Economics Discussion Paper $\mathrm{n}^{\circ}$ 630. Disponível em:<http://ssrn.com/abstract=1349971 >. Acesso em: 20/02/2013. 
WALD, Arnoldo. Dez anos de capital estrangeiro no mercado de capitais. In: WALD, Arnoldo (Org.). Doutrinas essenciais: volume 8; direito empresarial: mercado de capitais. São Paulo: Revista dos Tribunais, 2011.

WALD, Arnoldo. O governo das empresas. In: WALD, Arnoldo (Org.). Doutrinas essenciais: volume 3; direito empresarial : sociedade anônima. São Paulo: Revista dos Tribunais, 2011. 